\title{
Bridging the intention-behavior gap? The effect of plan-making prompts on job search and employment
}

\author{
MARTIN ABEL \\ RULOF BURGER \\ ELIANA CARRANZA \\ PATRIZIO PIRAINO
}

Stellenbosch Economic Working Papers: WP11/2018

www.ekon.sun.ac.za/wpapers/2018/wp112018

June 2018

KEYWORDS: Action Plan; Job Search; Active Labor Market Policy JEL: J64, J68, C93, D91 


\title{
Bridging the Intention-Behavior Gap? The Effect of
}

\section{Plan-Making Prompts on Job Search and Employment}

\author{
Martin Abel* $^{*}$ Rulof Burger ${ }^{\dagger} \quad$ Eliana Carranza ${ }^{\ddagger} \quad$ Patrizio Piraino $^{\S}$
}

\begin{abstract}
We test the effects of plan-making on job search and employment. In a field experiment with unemployed youths, participants who complete a detailed job search plan increase the number of job applications submitted (15\%) but not the time spent searching, consistent with intention-behavior gaps observed at baseline. Job seekers in the plan-making group diversify their search strategy and use more formal search channels. This greater search efficiency and effectiveness translate into more job offers $(30 \%)$ and employment (26\%). Weekly reminders and peer-support sub-treatments do not improve the impacts of plan-making, suggesting that limited attention and accountability are unlikely mechanisms.
\end{abstract}

\footnotetext{
*Harvard University. Email: abel@fas.harvard.edu

†Stellenbosch University. Email: rulof@sun.ac.za

${ }^{\ddagger}$ World Bank. Email: ecarranza@worldbank.org

$\S$ University of Cape Town. Email: patrizio.piraino@uct.ac.za

『Acknowledgement: This paper greatly benefited from comments by Rema Hanna, Lawrence Katz, Asim Khwaja, and Michael Kremer. Svetlana Pimkina provided superb research assistance. We also thank seminar participants at the University of California-Berkeley, University of Cape Town, Catholic University of Milan, and Harvard University. We thank the South African Department of Labour and J-PAL Africa, especially Laura Poswell, for assistance in the implementation of this project. The study was prepared as part of a collaboration with the World Bank Jobs Group and the Africa Gender Innovation Lab. We thank EuropeAid for financial support. All errors and omissions are our own.
} 


\section{Introduction}

Job search is a largely self-regulated undertaking. This requires job seekers to overcome a variety of psychological and behavioral challenges. Existing studies show, for example, that search intensity depends on job seekers' biases in beliefs about returns to search efforts (Spinnewijn, 2015), on their level of impatience (DellaVigna and Paserman, 2005), on their locus of control (Caliendo et al., 2015; McGee and McGee, 2016), as well as on their selfconfidence and willpower (Falk et al., 2006).

The focus of the present paper is on the so-called intention-behavior gap, defined as the disconnect between the intention to perform a particular behavior and the enactment of such behavior. We draw on insights from the psychology literature regarding the use of planmaking prompts to bridge the gap between intention and behavior. There is evidence that planning and scheduling tasks help people follow through on a variety of behaviors, ranging from voting (Nickerson and Rogers, 2010), to exercising (Prestwich et al., 2003), vaccinating (Milkman et al., 2011), and getting medical screening (Milkman et al., 2013). Rogers et al. (2015) and Hagger and Luszczynska (2014) provide recent reviews of this literature. We extend this research to the domain of job search.

We test the effect of plan-making on job search behavior and employment in a field experiment with a sample of 1,100 unemployed South African youth. As part of the job counseling workshops conducted by the South African Department of Labour, we prompt job seekers to complete a plan template. In the template, we first ask job seekers to fill a weekly chart with detailed day-by-day entries for whether, how and where they will search. We then ask them to add up their entries to weekly goals for how many hours to search and how many applications to submit. At baseline, treated job seekers report spending as much time searching as they intend to, but submitting fewer applications than their stated goal. Failure to follow through on applications may mean that they either fall short of their 
goals, or carry on low-effort activities (like browsing a job website) rather than high-effort activities (like preparing application materials), which arguably require more planning.

Five to twelve weeks after the intervention, we observe two main results. First, treated job seekers change their job search intensity, but only for the behavior for which we document an intention-behavior gap. Completing an action plan increases the number of job applications submitted by about $15 \%$ compared to participants who only attended the workshop, but does not affect the number of hours spent searching. ${ }^{1}$ We take this result as suggesting that the planning prompt increases the efficiency of search. That is, the plan induces a reallocation of time towards job search activities that result in submitted applications. We corroborate this result by informing participants about a vacancy and observing their actual behavior. Job seekers who completed a plan are $11 \%$ and $27 \%$ more likely to submit an application than the workshop-only group and pure control group, respectively.

Second, job seekers in the plan-making group use a wider range of search channels. In particular, they switch from predominantly using informal channels (e.g. talking to family and friends) to more formal channels (e.g. responding to advertisements). We interpret such diversification behavior as being consistent with diminishing returns to using a given channel. Indeed, diversification from informal to formal channels increases search effectiveness. These gains in search efficiency and search effectiveness translate into an increase in job offers (30\%) and employment (26\%) in the plan-making group.

Rogers et al. (2015) review the most prominent reasons proposed in the literature as to why plan-making prompts may work. First, action plans can help unpack complex tasks into specific activities, providing a realistic understanding of the required steps to follow through on intentions and the specific goals to focus on. Second, planning helps overcome forgetfulness and promote recall of the intended behavior. This can increase follow-through, as individuals are more likely to respond to environmental cues (Gollwitzer, 1999) and tasks

\footnotetext{
${ }^{1}$ We argue below that this is unlikely to be simply a result of greater noise in reported search hours.
} 
on their 'top of mind' (Karlan et al., 2016). Finally, action plans may serve as a commitment device. To the extent that individuals try to avoid the discomfort of failing to achieve a goal (Laibson, 1997), particularly in front of others (Prestwich et al., 2012), this will address procrastination. Indeed, planning has been shown to be more effective when individuals tell someone of their commitment (Stone et al., 1994).

In order to explore these mechanisms in the context of job search planning, our experimental design randomizes participants into two sub-treatments. Half of the group that completed the plan template was asked to nominate a person who could help them follow through on their search plans. This peer subsequently received text messages about the job seeker's search intentions. Peers are willing to serve this role and participants are very positive about how helpful this person was. However, this sub-treatment does not increase follow-through. We also send weekly reminders with their specific search goals to a random subset of job seekers. Although the reminder increases the likelihood that job seekers remember their search intentions by about $40 \%$, we do not find impacts of this sub-treatment either. This evidence, while not conclusive, suggests that commitment (or accountability) and limited attention are unlikely mechanisms in this context.

The results in the paper point to plan-making playing the role of helping unpack the different tasks of a multifaceted activity. Some tasks may demand higher or lower effort than others, and tasks may differ in their returns. ${ }^{2}$ In the absence of a plan that breaks up job search into well-specified tasks, individuals may be more prone to focus on low-effort/lowreturn tasks for a given amount of time devoted to search, falling short of their goals. In line with this explanation, we find that the specific search goals participants set themselves, after completing the detailed entries on the plan template, are a significant predictor of their subsequent change in search behavior.

\footnotetext{
${ }^{2}$ For instance, preparing an application and submitting it to job vacancy advertisements may require the same amount of time as contacting friends to inquire about jobs in their firms, but the probability of receiving a response and ultimately an offer as a result of these efforts may differ significantly.
} 
Our study makes a number of contributions to the literature. First, it extends research on intention-behavior gaps to the important domain of job search. While other studies evaluate job counseling programs that include elements of action planning, these are typically part of a package of interventions. ${ }^{3}$ We find that even in a context of high structural unemployment where search efforts are thought to make little difference to employment chances - addressing this particular behavioral bias improves job search intensity, with a potential to translate into real employment results.

Our paper also relates to a large literature on active labor market policies (ALMPs), particularly those aimed to boost job search intensity and efficacy (Card et al., 2015). In a recent review on the effectiveness of ALMPs in developing countries, the vast majority of studies find modest employment gains of about 2 percentage points (McKenzie, 2017). Likewise, we find that the government-run job counseling workshop increases employment by 1.9 percentage points. Our paper shows that simple design tweaks (i.e. adding a plan template to a workshop) addressing behavioral biases may improve the effectiveness of ALMPs (Babcock et al., 2012). Plan-making prompts are promising as they are low-cost, easy to implement, and preserve people's freedom of choice (Sunstein and Thaler, 2008).

Furthermore, our paper contributes to an established literature investigating the returns to different search channels (Holzer, 1988; Kuhn and Mansour, 2014; Kroft and Pope, 2014). Observational studies in this literature are challenged by the endogenous choice of search activities. Our experiment addresses this concern (at least partially) and indicates that there are high returns to diversifying search strategy. This evidence complements recent experimental results by Belot et al. (2016) who find that expanding the breadth of search to additional occupations has large returns in terms of job interviews.

\footnotetext{
${ }^{3}$ For example, Belot et al. (2016) report that the UK government's Behavioural Insight Team is testing a job counseling program that combines planning, monitoring, and resilience through creative writing. We could not confirm the details of the intervention (either online, or by contacting one of the researchers), but Belot et al. (2016) report that it is not possible to separate the effects of the various elements in the program (p.4).
} 
The rest of the paper proceeds as follows: Section 2 describes the research design and identification strategy; Section 3 reports the main results; Section 4 explores potential mechanisms; and Section 5 concludes.

\section{Study Design}

\subsection{Background and Study Sample}

While unemployment in South Africa is considered largely a structural problem, recent research has documented significant frictions in the labor market. ${ }^{4}$ The Department of Labour (DoL) is trying to address these market inefficiencies through a range of employment services including job counseling and job referrals. In the context of sluggish economic growth, however, public services are resource-constrained. In collaboration with the DoL, this study is part of an agenda to test innovative programs that are inexpensive and scalable.

Our sampling frame is the Employment Services of South Africa (ESSA) database, comprising of more than 550,000 job seekers collected by the DoL. We restricted this sampling frame to unemployed job seekers between the ages of 18 and 35, who registered with ESSA in the previous 18 months and lived within traveling distance from the three urban Labour Centres that were part of the study. ${ }^{5}$ From this sample, we randomly selected work seekers and contacted them using the phone number provided in ESSA. In the telephone call, surveyors invited job seekers to participate in an employment service study at the local Labour Center on a specified day. In return, they were offered a small stipend of 30 Rand (2.5 USD) that covered their travel cost. Of the individuals successfully contacted, approximately $67 \%$ agreed to participate, and of those who agreed, $63.5 \%$ came to the Labour Center on the

\footnotetext{
${ }^{4}$ Abel et al. (2017) document that reducing information asymmetries between hiring firms and job seekers through reference letters can improve match quality.

${ }^{5}$ We worked with the Labour Centres in Krugersdorp, Sandton and Soweto, in the Gauteng province.
} 
specified day. ${ }^{6}$

Our final study sample consists of 1,097 unemployed youths. Table 1 provides summary statistics. The sample is relatively educated (12.1 years of education, on average), with $79 \%$ having previously held a job. At baseline, participants are actively looking for work and spend about 11 hours per week on job search, incurring a cost of 77 Rand (about 6 USD). Despite this, the number of submitted applications (4.4 per month) is relatively low.

Table 1: Sample Characteristics

\begin{tabular}{lcccc}
\hline \hline & $\mathrm{N}$ & Mean & Median & $\mathrm{SD}$ \\
\hline Age & 1097 & 26.69 & 26 & 4.47 \\
Female & 1097 & .52 & 1 & .50 \\
Years of schooling & 1096 & 12.12 & 12 & 1.16 \\
Household size & 1097 & 2.36 & 2 & 1.91 \\
Moved to Johannesburg & 1097 & .30 & 0 & .46 \\
Ever employed & 1097 & .79 & 1 & .40 \\
Reservation wage & 1091 & 3162 & 3000 & 1833 \\
Fair wage & 1097 & 5800 & 5000 & 3209 \\
Job search transport cost & 1043 & 76.92 & 45 & 91.73 \\
Number employed friends & 1097 & 1.88 & 1 & 2.08 \\
Job search hours (week) & 1058 & 11.35 & 8 & 9.87 \\
Job applications (month) & 1087 & 4.36 & 3 & 5.26 \\
\hline \hline
\end{tabular}

Note: Table reports summary statistics at baseline. Winsorized at $95 \%$.

\subsection{Intervention Design}

We randomly assign participants to one of three treatment arms: Control (pure control), Workshop (workshop only), and Workshop Plus (workshop + plan making). Appendix Table A1 shows that there is balance across these experimental conditions on a number of variables at baseline. From about forty estimated p-values, we only see two significant difference in means at the $10 \%$ level.

\footnotetext{
${ }^{6}$ Higher educated job seekers are slightly more likely to be part of our sample, while gender and age do not predict whether people accepted the study invitation.
} 
The first treatment intervention is the standard 90-minute career-counseling workshop (Workshop) conducted by the Department of Labour. During the workshop, career counselors cover topics such as job search strategies, CV creation, interview techniques, and access to information and resources for job search. Thus, our design also allows us to evaluate one of the existing government programs in support of the unemployed.

Layered on top of the standard workshop is a job-search planning intervention (Workshop Plus). The 402 job seekers assigned to this treatment were provided with a plan template designed by the research team and were invited to create their personal job search plan. Respondents are first instructed to think about the time they have available in a typical week and to fill out a chart with the job search tasks they plan to perform on any given day of the week. Since increased detail orientation has been shown to improve follow-through on intentions (Rogers et al., 2015), respondents were encouraged to provide specific details regarding the how, when, and where of their proposed tasks (e.g. which newspaper to read, where to travel to search for work). ${ }^{7}$ After completing the chart, respondents are prompted to reflect on their proposed tasks and to reckon weekly goals for (i) the number of hours to spend searching, (ii) identified job opportunities, and (iii) submitted applications. At the end of the session, participants could take their plan with them. The plan template is provided in the Appendix.

A random subset of 206 job seekers in the plan-making group received a variation of the template in which they are additionally asked to identify a peer who can help them to follow up on their plans. The respondents in this Peer sub-treatment (workshop plus + peer) provide the contact information of the nominated peer, and their consent to contact her/him with information about their personal job search goals.

Finally, we randomized participants across the Workshop and Workshop Plus groups to

\footnotetext{
${ }^{7}$ Participants listed tasks that ranged across a spectrum of job search efforts (e.g. preparatory tasks such as document creation and certification, identification of opportunities, networking, and delivering CVs).
} 
receive text-message reminders about completing their job search goals before the end of the week. This Reminder sub-treatment differed for each group. The Workshop group received a general reminder to use the lessons learned in the workshop to identify job opportunities and apply for jobs. The Workshop Plus group received a specific reminder about the job search and application goals, as specified in the job seeker's plan (for the Peer sub-group, the peer also received a reminder) ${ }^{8}$ Participants in the control group did not receive a reminder. The study design is shown in Figure A1 in the Appendix.

\section{$2.3 \quad$ Data}

We collect data on study participants through in-person and phone interviews. Once participants arrived to the Labour Centres, surveyors first registered them and confirmed that their ID was among those scheduled for that day. Next, surveyors administered a baseline survey through an in-person interview. The survey takes on average 20 minutes and includes modules on demographic information, work history and current search activities. Baseline data was collected between September and December 2015.

Two rounds of follow-up data were collected, via phone, from all participants five and twelve weeks after the intervention. The attrition rate in the first and second follow-up round was $5 \%$ and 15\%, respectively, and did not differ by treatment group (Appendix Table A2).

In order to address concerns about mis-reports on the outcomes, we supplement the survey data with an observed measure of job search. This may be particularly relevant in the context of an intervention designed to assist job seekers. Specifically, we sent participants a text message (from a number they could not associate with the research study) in which we notified them of an actual vacancy and invited them to submit an application to a specific

\footnotetext{
${ }^{8}$ The content of the text-message reminder for each group was the following. Workshop group: "Dear XX. Labour Centre Reminder: Apply the steps you learned in the job search workshop about finding job opportunities and applying for jobs." Workshop Plus group: "Dear XX (Dear YY). Labour Centre Reminder: Your (Your friend $X X$ 's) plan-making is to search for $X$ hours, find $X$ job opportunities and apply for $X$ jobs by Sunday."
} 
email address. This allowed us to observe whether the participants sent an application in response to the message, as well as the application material that was submitted. ${ }^{9}$

Furthermore, we collected a copy of the completed job-search plans and transcribed their content. Table 2 provides statistics of the plans in terms of completion rates, number of days (per week) containing a planned activity, the weekly goal number of hours to spend on job search activities, the weekly goal number of job opportunities to identify, and the weekly goal number of applications to submit.

Table 2: Action Plan Descriptives

\begin{tabular}{lccc}
\hline \hline & $\mathrm{N}$ & Mean & $\mathrm{SD}$ \\
\hline Completed AP & 402 & .89 & .32 \\
Activity-days & 357 & 3.75 & 2.38 \\
Goal: Job search hours & 345 & 8.46 & 5.78 \\
Goal: Opportunities to identify & 339 & 10.35 & 6.5 \\
Goal: Applications to submit & 340 & 7.82 & 4.33 \\
\hline \hline
\end{tabular}

Note: Characteristics of transcribed action plans. Activitydays refer to number of days on which an activity was listed. Respondents listed goal hours, opportunities and applications following the weekly breakdown of activities.

We construct a measure of the intention-behavior gap by comparing search intentions listed in the plans with reported behavior at baseline. We find that, on average, respondents aim to submit 6.6 more job applications per week than they actually do (median difference of 5.5 applications). This indicates the presence of an intention-behavior gap. ${ }^{10}$ On the other hand, respondents aim to spend on average 3.4 hours less time on job search activities

\footnotetext{
${ }^{9}$ The message informed participants about a real vacancy in a specific sector; whenever possible in a sector in which they worked before. For those with work experience in more than one sector, we randomly picked one. Sectoral shares were balanced by treatment status. We submitted (forwarded) the applications we received to the vacancies, on the participants' behalf. This was done after the last follow-up survey to avoid confounding employment estimates.

${ }^{10}$ Baseline behavior is collected by asking "In a typical week, how many applications do you submit / hours do you search". Ideally, we would have collected the intention and behavior measure for exactly the same time period, but this was not feasible as the formation of the intention was part of the treatment.
} 
per week than what they indicate at baseline. However, the distribution is centered around zero hours, and the median and modal difference between goal and actual hours searched at baseline are exactly zero (Figure 1).
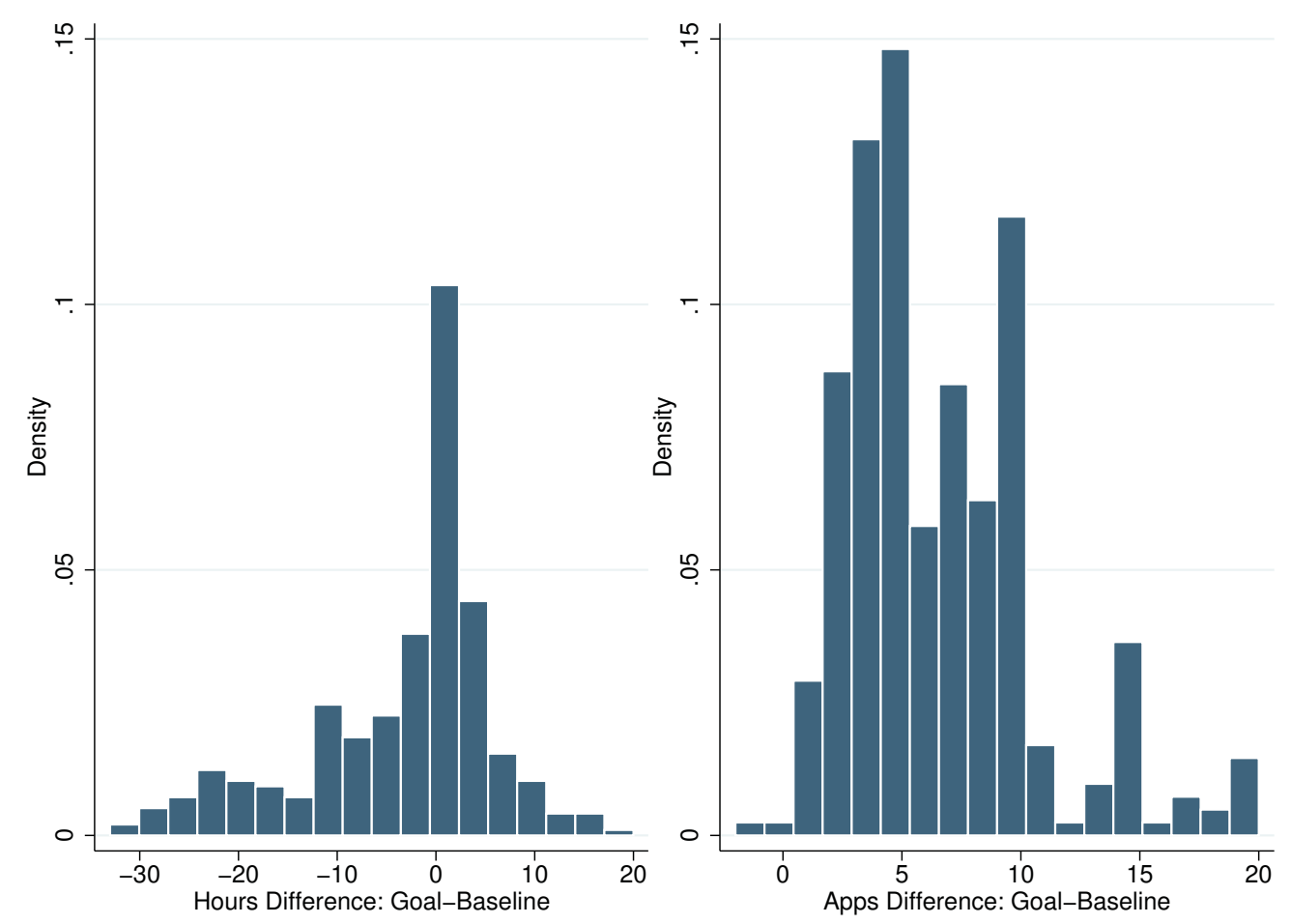

Notes: Distribution of the difference between search intentions (search hours and submitted applicaitions) listed in the plans and reported behavior at baseline.

Figure 1: Intention-Behaviour Gap: Difference at Baseline

The data thus suggests that there is an intention-behavior gap in terms of applications submitted, but not in terms of time spent searching. This will be important for the empirical analysis as it provides differential predictions about search outcomes. If the planning intervention is addressing an intention-behavior gap, then we would expect to see an effect on the number of applications, but no effect on the time spent searching. ${ }^{11}$

\footnotetext{
${ }^{11} \mathrm{~A}$ possible concern is that individuals may find it difficult to track the time spent searching, whereas applications are more tangible. We find, however, that the 'hours searched' variable is informative. First, it varies in the expected way with aspects of search behavior (e.g. use of more/less time-consuming search channels/activities) and individual attributes (e.g. women spend less time). Secondly, the estimated effect of the intervention on hours searched is a relatively precise zero, which suggests that the result is not driven
} 


\subsection{Empirical Strategy}

Our primary objective is to assess the effects of the treatments on job search behavior and labor market outcomes. To increase statistical power, we pool the two rounds of follow-up data and estimate the following equation:

$$
Y_{i j t}=\alpha_{0}+\beta_{1} \text { Workshop }_{i}+\beta_{2} \text { WorkshopPlus }_{i}+\delta X_{i 0}+\lambda_{j}+\gamma_{t}+e_{i}
$$

where $Y_{i j t}$ is the outcome indicator for individual $i$ in location $j$ at time $t . X_{i 0}$ is a vector of covariates, including age, gender, education, household size, and primary language. Location fixed effects $\lambda_{j}$ account for geographical differences in labor demand, and time dummies $\gamma_{t}$ indicate the follow-up round (a value of 1 signifies the second). Errors are clustered at the individual level to account for the panel structure of the data.

Note that Workshop and Workshop Plus include, respectively, participants in the workshop only and the workshop plus plan-making treatment arms. Equation (1) thus estimates our main treatment effects. The peer support and reminder sub-treatment effects will be estimated and reported in Section 4. Note also that because completion of the action plan was not perfect (around 90\%), our results are intent-to-treat estimates.

\section{Main Results}

\subsection{Search Intensity and Efficiency}

We examine job search intensity in terms of the number of hours respondents spend searching for a job and the number of completed applications. Table 3 indicates that there is no change in the number of hours spent searching in either the Workshop or Workshop Plus groups. by noise in the dependent variable. Classical measurement error would instead reduce precision, without inducing bias. 
This zero effect is not driven by imprecise estimates. Instead, the estimated coefficients themselves are small and never exceed $3.5 \%$ of the control mean.

Table 3: Effects on Job Search Intensity

\begin{tabular}{lcccc}
\hline \hline & $(1)$ & $(2)$ & $(3)$ & $(4)$ \\
& Search Hours & Search Hours & Applications & Applications \\
\hline WS Basic & 0.225 & 0.016 & 0.163 & 0.124 \\
& $(0.897)$ & $(0.897)$ & $(0.274)$ & $(0.273)$ \\
WS Plus & -0.243 & -0.480 & $0.749^{* * *}$ & $0.681^{* * *}$ \\
& $(0.750)$ & $(0.747)$ & $(0.240)$ & $(0.235)$ \\
Covariates & $N o$ & $Y e s$ & $N o$ & $Y e s$ \\
\hline Observations & 1888 & 1886 & 1896 & 1895 \\
$R^{2}$ & 0.083 & 0.092 & 0.308 & 0.318 \\
Control Mean & 14.095 & 14.095 & 3.835 & 3.835 \\
P-value & 0.595 & 0.573 & 0.054 & 0.062 \\
\hline \hline
\end{tabular}

Notes: ${ }^{*} \mathrm{p}<0.10,{ }^{* *} \mathrm{p}<0.05,{ }^{* * *} \mathrm{p}<0.01$. Standard errors (reported in parentheses) are clustered at the individual level. P-value compares WS Plus to WS Basic.

All regressions control for location-fixed effects and baseline value of the outcome variable. Outcome variables are winsorized at the $5 \%$ level.

In contrast, there is a significant increase in the number of applications in the Workshop Plus group, but not in the Workshop group, relative to the control mean. The number of applications is also significantly higher in the Workshop Plus group relative to the Workshop group, indicating that plan-making is driving the effect. At follow up, the Workshop Plus group submits 0.7 additional applications, which is $15 \%$ more than the Workshop group and $18 \%$ more than the Control group. While this is a sizable increase relative to the low number of applications at baseline, it only partially closes the intention-behavior gap.

We corroborate the latter results by re-estimating Equation (1) with an observed measure of application submission. We anonymously inform job seekers about an actual vacancy and invite them to submit an application to a specific email address. We observe whether they 
apply for the job, as well as the material included with their application. Subjects who completed the action plan were 5.3 percentage points (27\% increase) and 2 percentage points (11\% increase) more likely to submit an application in response to our message regarding a vacancy, compared to the Control and Workshop groups respectively. Although less precisely estimated, these impacts are qualitatively similar to those we obtain using self-reported data.

These findings provide evidence that intention-behavior gaps are of relevance in the context of job search. In particular, our set of estimates implies that there is an increase in the ratio of applications submitted to the number of hours searched. Indeed, the Workshop Plus group submits $20 \%$ more applications per hour spent searching relative to the control mean. We interpret this result as an increase in search efficiency.

\subsection{Employment}

We next investigate whether the increase in application submissions translates into better employment-related outcomes. In Table 4, we show the treatment effects on responses from employers, job offers, and employment likelihood.

Compared to the Workshop group, job seekers in the Workshop Plus group receive a higher number of responses from employers (24\%) and job offers (30\%), and were more likely to be employed (26\%) at the time of follow-up. The estimated coefficients on Workshop Plus are generally significantly different from both the Control and Workshop groups, with the exception of the employment effect of Workshop Plus relative to Workshop (Columns 5 and 6). Nonetheless, the difference in the point estimates of the employment effects between Workshop Plus and Workshop is sizable and consistent with the effects on the intermediate outcomes.

These results suggest that a simple design tweak such as adding a plan-making component to a standard government-run counseling workshop can substantially boost its effectiveness. The point estimate of the impact of the standard workshop on the likelihood of employment is 
1.9 percentage points. This is very much in line with global evidence on the limited impact of information provision, counseling programs, and a broader range of ALMPs (Altmann et al., 2015; Card et al., 2015; McKenzie, 2017). On the other hand, the effect of the Workshop Plus intervention is 4.9 percentage points.

Table 4: Effects on Employment Outcomes

\begin{tabular}{|c|c|c|c|c|c|c|}
\hline & $\begin{array}{c}(1) \\
\text { Responses }\end{array}$ & $\begin{array}{c}(2) \\
\text { Responses }\end{array}$ & $\begin{array}{c}(3) \\
\text { Offers }\end{array}$ & $\begin{array}{c}(4) \\
\text { Offers }\end{array}$ & $\begin{array}{c}(5) \\
\text { Employed }\end{array}$ & $\begin{array}{c}(6) \\
\text { Employed }\end{array}$ \\
\hline WS Basic & $\begin{array}{c}-0.025 \\
(0.058)\end{array}$ & $\begin{array}{c}-0.027 \\
(0.059)\end{array}$ & $\begin{array}{c}0.023 \\
(0.022)\end{array}$ & $\begin{array}{c}0.022 \\
(0.022)\end{array}$ & $\begin{array}{c}0.021 \\
(0.025)\end{array}$ & $\begin{array}{c}0.019 \\
(0.025)\end{array}$ \\
\hline WS Plus & $\begin{array}{c}0.112^{* *} \\
(0.053)\end{array}$ & $\begin{array}{c}0.102^{*} \\
(0.053)\end{array}$ & $\begin{array}{l}0.058^{* * *} \\
(0.020)\end{array}$ & $\begin{array}{l}0.061^{\text {*** }} \\
(0.020)\end{array}$ & $\begin{array}{c}0.047^{* *} \\
(0.020)\end{array}$ & $\begin{array}{c}0.049^{* *} \\
(0.021)\end{array}$ \\
\hline Covariates & No & Yes & No & Yes & No & Yes \\
\hline Observations & 1895 & 1894 & 1882 & 1881 & 1971 & 1969 \\
\hline$R^{2}$ & 0.101 & 0.109 & 0.012 & 0.021 & 0.017 & 0.024 \\
\hline Control Mean & 0.544 & 0.544 & 0.130 & 0.130 & 0.115 & 0.115 \\
\hline $\mathrm{P}$-value & 0.027 & 0.036 & 0.126 & 0.099 & 0.321 & 0.249 \\
\hline
\end{tabular}

Notes: ${ }^{*} \mathrm{p}<0.10,{ }^{* *} \mathrm{p}<0.05,{ }^{* * *} \mathrm{p}<0.01$. Regressions use panel data over two follow-up periods.

Standard errors (reported in parentheses) are clustered at the individual level. P-value compares WS Plus to WS Basic.

All regressions control for location-fixed effects and baseline value of the outcome variable.

Outcome variables are winsorized at the $5 \%$ level.

It is also worth noting that our data shows that the jobs found by participants in the Workshop Plus group do not differ with regard to salary or job satisfaction compared to both the Control and Workshop groups (results not reported). This suggests that the positive employment effect of plan-making does not come at the cost of inducing individuals to apply to (and accept) lower quality jobs.

\subsection{Search Strategy}

The results in the previous sections (Tables 3 and 4) indicate that job offers increase by twice the margin than applications (30\% vs. 15\%) in response to our plan-making treatment. This suggests that the action plan not only led participants to submit more applications, but also 
that each application was more effective in obtaining job offers. This greater effectiveness may stem from higher-quality applications, or from job seekers diverting to search strategies with higher returns, or both.

To shed light on the quality of applications, we analyze job seekers' submissions in response to the vacancy notification sent by the research team. We examine whether the applications followed the appropriate format, contained motivational statements and included necessary documents. Appendix Table A3 shows that participants in the Workshop Plus group submitted applications of slightly higher quality compared to the Control group (though the difference is not significant), but of very similar quality to the Workshop group. Thus, the quality of applications is unlikely to explain the larger number of job offers in the plan-making group relative to the workshop group.

To explore changes in search strategy, we estimate treatment effects on job seekers' use of different search channels. Table 5 shows that participants who completed the job-search plan significantly increased the frequency at which they visited employment agencies, dropped CVs, answered advertisements, and searched online, with respect to both the control and the workshop groups. ${ }^{12}$ In contrast, although the standard workshop includes counseling on a variety of search strategies, no significant effect was observed on participants in the standard workshop.

Completing and submitting application materials is arguably a high-effort task, in terms of both complexity and psychological costs, typically preceded by lower-effort tasks such as networking and identifying job openings. This may explain why at baseline we observe that job seekers more frequently turn to family and friends to find a job, while relying less on strategies such as approaching employment agencies, responding to jobs announcements, and dropping CVs directly to firms, which likely require preparing an application.

\footnotetext{
${ }^{12}$ The OLS results in Table 5 do not have a simple behavioral interpretation as the dependent variable is an ordinal search frequency variable. Table A4 in the Appendix re-estimates the model using an interval regression. The results are qualitatively very similar to those obtained in Table 5 .
} 
Table 5: Effects on Frequency of Search Channel Use

\begin{tabular}{|c|c|c|c|c|c|c|}
\hline & $\begin{array}{c}(1) \\
\text { Empl Agency }\end{array}$ & $\begin{array}{c}(2) \\
\text { Dropped CV }\end{array}$ & $\begin{array}{c}(3) \\
\text { Placed Ad }\end{array}$ & $\begin{array}{c}(4) \\
\text { Answered Ad }\end{array}$ & $\begin{array}{c}(5) \\
\text { Searched Online }\end{array}$ & $\begin{array}{c}\text { (6) } \\
\text { Fam/Friends }\end{array}$ \\
\hline WS Basic & $\begin{array}{c}-0.016 \\
(0.139)\end{array}$ & $\begin{array}{c}-0.140 \\
(0.131)\end{array}$ & $\begin{array}{c}0.060 \\
(0.144)\end{array}$ & $\begin{array}{c}-0.068 \\
(0.122)\end{array}$ & $\begin{array}{c}0.058 \\
(0.130)\end{array}$ & $\begin{array}{c}-0.048 \\
(0.102)\end{array}$ \\
\hline WS Plus & $\begin{array}{l}0.362^{* * *} \\
(0.123)\end{array}$ & $\begin{array}{l}0.253^{* *} \\
(0.115)\end{array}$ & $\begin{array}{c}0.153 \\
(0.119)\end{array}$ & $\begin{array}{l}0.301^{* * *} \\
(0.107)\end{array}$ & $\begin{array}{l}0.410^{* * *} \\
(0.100)\end{array}$ & $\begin{array}{c}-0.021 \\
(0.081)\end{array}$ \\
\hline Observations & 1937 & 1936 & 1934 & 1927 & 1931 & 1926 \\
\hline$R^{2}$ & 0.093 & 0.069 & 0.028 & 0.088 & 0.364 & 0.045 \\
\hline Control Mean & 2.125 & 2.826 & 1.532 & 3.253 & 4.203 & 4.839 \\
\hline P-value & 0.010 & 0.004 & 0.537 & 0.003 & 0.006 & 0.786 \\
\hline
\end{tabular}

However, to the extent that there are diminishing returns to the use of search channels, a reallocation of emphasis to less utilized (and higher effort) channels is expected to improve job search effectiveness. Consistently, we find that contacting family and friends and placing advertisements are unaffected by the plan-making intervention. Instead, job seekers in the Workshop Plus group diversify their search strategy by intensifying the use of channels that possibly enjoy steeper returns. This, in turn, can help explain the employment effects observed in Section 3.2. ${ }^{13}$

In summary, plan-making helps job-seekers optimize their search strategy. This not only increases search efficiency (as indicated by the greater number of applications submitted for a given time effort) but it may also improve search effectiveness, in terms of greater employment returns to each application submitted.

\footnotetext{
${ }^{13}$ Indeed, we find that the increase in hours spent searching is positively correlated with job responses and offers only for channels such as answering advertisements, visiting employment centers, or dropping off CVs, which likely require preparing an application (results not reported). In addition, job seekers in the plan-making group are significantly more likely to report that they found employment by answering advertisements.
} 


\section{Why did Participants Fail to Optimize Job Search?}

Our main findings suggest that plan-making led participants to spend their job search time more efficiently, to adopt more effective search strategies, and to obtain employment gains. This raises the question of why people failed to intensify and optimize their job search at the outset of the study. We investigate the role of the three most prominent behavioral barriers that plan-making can help address: the complexity of multifaceted tasks, forgetfulnesses, and lack of commitment (Rogers et al., 2015). Of course, there are other potential mechanisms, which renders the analysis in this section suggestive rather than conclusive.

\section{$4.1 \quad$ Unpacking}

Plan-making can help unpack a complex multifaceted task into smaller subtasks, providing a more realistic sense of the logistical steps and time required to complete an activity (Kruger and Evans, 2004; Buehler et al., 1994). One way of unpacking a daunting task (finding a job) is to set detailed plans regarding how, when and where to perform a subtask (e.g. looking for ads in the newspaper every morning). Another is to set concrete goals with respect to specific subtasks (e.g. identifying three vacancies) rather than the desired outcome (finding work).

Our plan-making treatment asks participants to unpack their search process in both of these ways. First, participants fill a detailed chart with specific subtasks for specific days of the week. After completing this chart, they set weekly goals (in line with their detailed plan) on the number of job opportunities to identify, applications to submit, and hours to spend searching.

We find a strong positive association between the stated goals on participants' plans and subsequent behavior changes. ${ }^{14}$ In Table 6, we show that job seekers who set a higher

\footnotetext{
${ }^{14}$ Due to the experimental design, we can only estimate this correlation for participants who completed the action plan. In addition, we do not have information on the number of identified job opportunities at
} 
goal in terms of search hours are more likely to have increased the time spent searching at follow-up. An additional hour in their stated goal is associated with a 0.4 hour increase, from baseline, in actual behavior (Columns 2 and 3). A positive correlation is also found between goals and behavior change in terms of submitted applications. A unit addition in the stated goal is associated to a 0.11 increase in applications (Columns 4 and 6). Notably, goals are significant predictors only of a change in the corresponding behavior, suggesting that the observed pattern is not driven by motivation or other unobservable character traits. ${ }^{15}$

Table 6: Action Plan Subgroup Analysis: Correlation with Search Intensity

\begin{tabular}{|c|c|c|c|c|c|c|}
\hline & \multicolumn{3}{|c|}{ Search Hours } & \multicolumn{3}{|c|}{ Submitted Applications } \\
\hline & $(1)$ & $(2)$ & $(3)$ & $(4)$ & $(5)$ & $(6)$ \\
\hline & Search Hours & Search Hours & Search Hours & Applications & Applications & Applications \\
\hline Goal: Applications & -0.131 & & $-0.267^{* *}$ & $0.113^{* *}$ & & $0.106^{*}$ \\
\hline & $(0.119)$ & & $(0.119)$ & $(0.055)$ & & $(0.054)$ \\
\hline \multirow[t]{2}{*}{ Goal: Hours } & & $0.405^{* * *}$ & $0.460^{* * *}$ & & 0.048 & 0.035 \\
\hline & & $(0.105)$ & $(0.107)$ & & $(0.037)$ & $(0.036)$ \\
\hline Observations & 582 & 590 & 576 & 580 & 589 & 574 \\
\hline$R^{2}$ & 0.177 & 0.207 & 0.218 & 0.352 & 0.341 & 0.358 \\
\hline Baseline Mean & 12.013 & 12.013 & 12.013 & 4.647 & 4.647 & 4.647 \\
\hline
\end{tabular}

The evidence of a positive correlation between goals and behavior change for participants in the plan-making treatment group is consistent with studies in the psychology literature showing that goal-directed actions (i.e. implementation intentions) can support goal achievement. See Brandstätter et al. (2001) for a review. ${ }^{16}$

follow-up, which implies that we cannot check the correlation between goals and behavior for this variable.

${ }^{15}$ Column 1 in Table 6 shows that the intended search hours are not correlated with subsequent changes in submitting applications, while Column 5 shows that the intended applications are uncorrelated with changes in hours searched.

${ }^{16}$ van Hooft and Noordzij (2009) experimentally test the effectiveness of a workshop focused on goal setting. They find suggestive evidence of a positive effect on search intensity and employment. However, the study is limited by a small sample size and selective attrition. 


\subsection{Forgetfulness}

We explore next whether the effect of our intervention may be related to bringing job search at the 'top of mind' (Karlan et al., 2016). While the action plan may itself serve as a reminder, we strengthen this channel by sending weekly SMS reminders about job search goals to a subset of participants. ${ }^{17}$

We find that reminders do not have a significant impact on search behavior or employment outcomes (Appendix Table A5). General SMS reminders about job search steps to participants in the standard workshop did not increase the number of hours spent searching or applications submitted. Similarly, sending specific reminders about job seekers' weekly goals to those who had completed the job search plan did not change their search intensity.

A possible explanation for this result is that participants ignore the SMS reminders or that they do not process the content of the message. We find, however, that reminders significantly increase the likelihood that the plan-making group could correctly recall their goals at follow-up (three months post-intervention) by approximately 22 percentage points-a $41 \%$ impact (Table 7, Column 1). Conditional on claiming that they remember, the recall of actual goals is similarly accurate across groups (Table 7, Column 2).

It is also possible that because the action plan itself already serves as a reminder, bringing job search to top of mind, it limits the additional potential impact of the SMS. However, the finding that reminders are also ineffective in the group that did not complete any plan renders this explanation less plausible. Overall, we believe that these results suggest that forgetfulness may not be the limiting factor for the job seekers in our sample.

\footnotetext{
${ }^{17}$ SMS reminders have been effective in different domains, from savings (Karlan et al., 2016) to physical activity (Schwerdtfeger et al., 2012). Alternative forms of reminder have also been used to strengthen planning prompts. For instance, writing down the details of a medical appointment on a post-it note addresses forgetfulness, increasing by $16 \%$ the probability of receiving a colonoscopy (Milkman et al., 2013).
} 
Table 7: Second Follow Up: Goal Recall

\begin{tabular}{lcc}
\hline \hline & $(1)$ & $(2)$ \\
& Recall Likelihood & Recall Accuracy \\
\hline Reminder & $0.215^{* * *}$ & 0.037 \\
& $(0.059)$ & $(0.616)$ \\
\hline Observations & 253 & 140 \\
$R^{2}$ & 0.130 & 0.100 \\
Control Mean & 0.527 & 3.491 \\
\hline \hline
\end{tabular}

Notes: ${ }^{*} \mathrm{p}<0.10,{ }^{* *} \mathrm{p}<0.05,{ }^{* * *} \mathrm{p}<0.01$. Regressions use data from the second follow-up.

Robust standard errors (reported in parentheses). Outcomes are likelihood of remembering the goal number of applications, and the absolute difference between stated goal and recalled goal.

All regressions control for location-fixed effects. Outcome variables are winsorized at the $5 \%$ level.

\subsection{Accountability}

Plan-making could also serve as a commitment device, as failing to follow through on intended behavior may cause discomfort (Cialdini, 2009). Reminders of the respondent's intentions could lead to increased accountability. However, as shown above, we find no evidence that reminders affect behavior.

Alternatively, we draw on the peer support intervention to directly test the importance of accountability. Stone et al. (1994) find that social pressure can effectively induce committment to intended behavior. Rogers et al. (2015) argue that planning prompts are more effective when family or friends are informed of the plan, since this increases the discomfort of failure to follow through. ${ }^{18}$ If our intervention operates mainly by helping individuals commit to a plan of action, then we may expect to see stronger effects when a peer commitment mechanism is added.

The data show that peer support does not lead to an increase in job search intensity beyond the impacts of plan-making itself (Appendix Table A6). That is, participants who completed a job search plan have similar outcomes whether or not they nominated a peer to

\footnotetext{
${ }^{18}$ Our study participants mainly nominated friends (48\%) and nuclear family members (42\%) to receive periodic notifications about the job seeker's search goals. These close peers may be particularly instrumental in creating a sense of accountability and social pressure.
} 
help them follow through on their intentions.

A possible reason may be that the nominated peers were not willing to serve that role. Our design, however, allowed them to easily opt out if they wanted to, and we find that virtually none of the support peers refused. ${ }^{19}$ Furthermore, participants engaged with their peers. In the follow-up survey, $85 \%$ reports that the peer helped them in their job search. Participants list various ways, other than social pressure, through which peers facilitated their job search, including information provision (60\%), searching on the respondent's behalf (21\%), and providing financial help (14\%). Nonetheless, the fact that the peer support does not affect any search or employment outcomes suggests that neither the commitment nor any of the other support channels facilitates job search in our context.

It is of course possible that participants may have been already utilizing their social network in their job search. In fact, over $95 \%$ of respondents reported discussing job search with family and friends at baseline. However, the peer support intervention is equally ineffective regardless of how frequently they discussed job search before our intervention (results not reported). Overall, we intepret these results as evidence that our action plan intervention is unlikely to work through increased commitment and accountability.

\section{Conclusion}

A substantial body of work in the psychology literature demonstrates that planning prompts can help individuals overcome the intention-behavior gap (i.e. the disconnect between the intention to perform and the actual enactment of a behavior) in a number of contexts. We draw on insights from this literature to add a novel element to one of the most studied areas in labor economics and policy: job search. In particular, we test the effects of planning

\footnotetext{
${ }^{19}$ Initial message to peer: "Dear $X X . Y Y$ identified you as a good person to help him/her follow his/her job search plan. You will receive regular reminders about YY's search goals. If you do NOT want to receive these messages, text: OUT. Thank you. Labour Centre."
} 
prompts on job search intensity and employment outcomes.

Our main results indicate that completing a job search plan helps unemployed youths to be more efficient and effective in their job search. We show that plan-making allows individuals to increase the number of applications submitted and to diversify their portfolio of search channels. These effects can help explain the employment gains we observe in our sample and provide first evidence (to the best of our knowledge) on the promise of pure plan-making interventions in the context of job search.

The results presented in the paper are of obvious policy relevance, given the modest impacts of active labor market policies documented in a variety of contexts (McKenzie, 2017). We suggest that a simple low-cost design tweak, such as adding a plan-making activity to standard government-run job counseling workshops, can substantially boost the effectiveness of existing programs.

Our finding of high returns to job search intensity for young seekers in South Africa may appear puzzling if one considers the large number of unemployed youth in the country who are unsuccessfully looking for work. However, it may be precisely in such contexts that plan-making is most effective. If negative feedback from failed search efforts leads to discouragement and inefficient job search, behaviorally-informed interventions that help individuals increase their search intensity can have significant employment effects.

Although our results show the relevance of intention-behavior gaps in the domain of job search and the impacts of plan-making prompts on search intensity, some questions are left unanswered. First, our experimental design does not allow us to identify the general equilibrium employment effects of this intervention, which may of course be different from the partial effects presented here. Moreover, while our evidence suggests that the value of planmaking derives mainly from helping job-seekers unpack the complicated job search process into smaller tasks and more concrete goals, further tests of this specific mechanism may be needed. Finally, unlike other actions investigated in the literature on intention-behavior 
gaps (e.g. voting or vaccinating), job search is a continued activity. Future research could explore interventions that can help sustain the observed (short-term) effects, for instance by allowing job seekers to update their job search plans in the face of failed efforts.

Overall, our results are consistent with research in social psychology suggesting that the stronger the intentions to perform a certain behavior, the higher the likelihood of overlooking tools that can help increase follow-through. This is due to the erroneous belief that strong intentions will more easily translate into actions (Koehler et al., 2011). Plan-prompting interventions can therefore be particularly effective for increasing follow-through on intentions of high importance, like searching for work. 


\section{References}

Abel, M., R. Burger, and P. Piraino (2017). The value of reference letters. Technical report, Working paper, Harvard University.

Altmann, S., F. Armin, S. Jäger, and F. Zimmermann (2015). Learning about job search: A field experiment with job seekers in germany. Working Paper.

Babcock, L., W. J. Congdon, L. F. Katz, and S. Mullainathan (2012). Notes on behavioral economics and labor market policy. IZA Journal of Labor Policy 1(1), 1-14.

Belot, M., P. Kircher, and P. Muller (2016). Providing advice to job seekers at low cost: An experimental study on online advice. IZA DP No. 10068.

Brandstätter, V., A. Lengfelder, and P. M. Gollwitzer (2001). Implementation intentions and efficient action initiation. Journal of personality and social psychology 81(5), 946.

Buehler, R., D. Griffin, and M. Ross (1994). Exploring the" planning fallacy": Why people underestimate their task completion times. Journal of personality and social psychology $67(3), 366$.

Caliendo, M., D. A. Cobb-Clark, and A. Uhlendorff (2015). Locus of control and job search strategies. Review of Economics and Statistics 97(1), 88-103.

Card, D., J. Kluve, and A. Weber (2015). What works? a meta analysis of recent active labor market program evaluations. Technical report, National Bureau of Economic Research.

Cialdini, R. (2009). Influence: The power of persuasion. New York: William Morrow.

DellaVigna, S. and M. D. Paserman (2005). Job search and impatience. Journal of Labor Economics 23(3), 527-588.

Falk, A., D. Huffman, and U. Sunde (2006). Self-confidence and search. IZA DP No. 2525. 
Gollwitzer, P. M. (1999). Implementation intentions: strong effects of simple plans. American psychologist 54(7), 493.

Hagger, M. S. and A. Luszczynska (2014). Implementation intention and action planning interventions in health contexts: State of the research and proposals for the way forward. Applied Psychology: Health and Well-Being 6(1), 1-47.

Holzer, H. J. (1988). Search method use by unemployed youth. Journal of Labor Economics 6(1), 1-20.

Karlan, D., M. McConnell, S. Mullainathan, and J. Zinman (2016). Getting to the top of mind: How reminders increase saving. Management Science.

Koehler, D. J., R. J. White, and L. K. John (2011). Good intentions, optimistic selfpredictions, and missed opportunities. Social Psychological and Personality Science 2(1), $90-96$.

Kroft, K. and D. G. Pope (2014). Does online search crowd out traditional search and improve matching efficiency? evidence from craigslist. Journal of Labor Economics 32(2), 259-303.

Kruger, J. and M. Evans (2004). If you don’t want to be late, enumerate: Unpacking reduces the planning fallacy. Journal of Experimental Social Psychology 40(5), 586-598.

Kuhn, P. and H. Mansour (2014). Is internet job search still ineffective? The Economic Journal 124(581), 1213-1233.

Laibson, D. (1997). Golden eggs and hyperbolic discounting. The Quarterly Journal of Economics 112(2), 443-478.

McGee, A. and P. McGee (2016). Search, effort, and locus of control. Journal of Economic Behavior $\&$ Organization 126, 89-101. 
McKenzie, D. (2017). How Effective Are Active Labor Market Policies in Developing Countries? A Critical Review of Recent Evidence. The World Bank.

Milkman, K. L., J. Beshears, J. J. Choi, D. Laibson, and B. C. Madrian (2011). Using implementation intentions prompts to enhance influenza vaccination rates. Proceedings of the National Academy of Sciences 108(26), 10415-10420.

Milkman, K. L., J. Beshears, J. J. Choi, D. Laibson, and B. C. Madrian (2013). Planning prompts as a means of increasing preventive screening rates. Prev Med 56(1), 92-3.

Nickerson, D. W. and T. Rogers (2010). Do you have a voting plan? implementation intentions, voter turnout, and organic plan making. Psychological Science 21(2), 194-199.

Prestwich, A., M. T. Conner, R. J. Lawton, J. K. Ward, K. Ayres, and R. R. McEachan (2012). Randomized controlled trial of collaborative implementation intentions targeting working adults' physical activity. Health Psychology 31(4), 486.

Prestwich, A., R. Lawton, and M. Conner (2003). The use of implementation intentions and the decision balance sheet in promoting exercise behaviour. Psychology and Health 18(6), $707-721$.

Rogers, T., K. L. Milkman, L. K. John, and M. I. Norton (2015). Beyond good intentions: Prompting people to make plans improves follow-through on important tasks. Behavioral Science $\mathscr{G}$ Policy 1(2), 33-41.

Schwerdtfeger, A. R., C. Schmitz, and M. Warken (2012). Using text messages to bridge the intention-behavior gap? a pilot study on the use of text message reminders to increase objectively assessed physical activity in daily life. Frontiers in psychology 3, 270.

Spinnewijn, J. (2015). Unemployed but optimistic: Optimal insurance design with biased beliefs. Journal of the European Economic Association 13(1), 130-167. 
Stone, J., E. Aronson, A. L. Crain, M. P. Winslow, and C. B. Fried (1994). Inducing hypocrisy as a means of encouraging young adults to use condoms. Personality and Social Psychology Bulletin 20(1), 116-128.

Sunstein, C. and R. Thaler (2008). Nudge. The politics of libertarian paternalism. New Haven.

van Hooft, E. A. and G. Noordzij (2009). The effects of goal orientation on job search and reemployment: A field experiment among unemployed job seekers. Journal of Applied Psychology 94(6), 1581. 


\section{Appendix}

Control

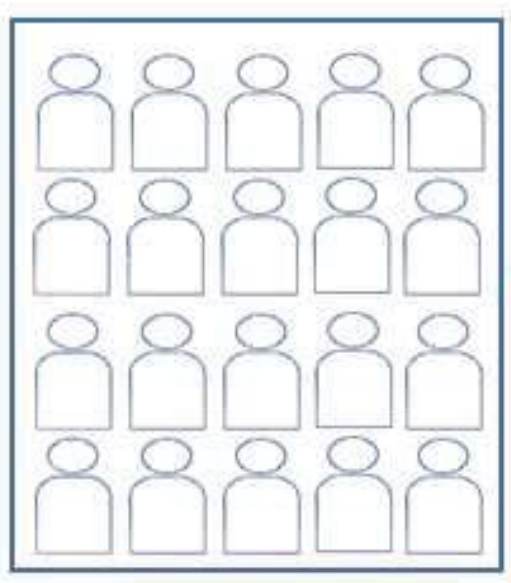

Workshop

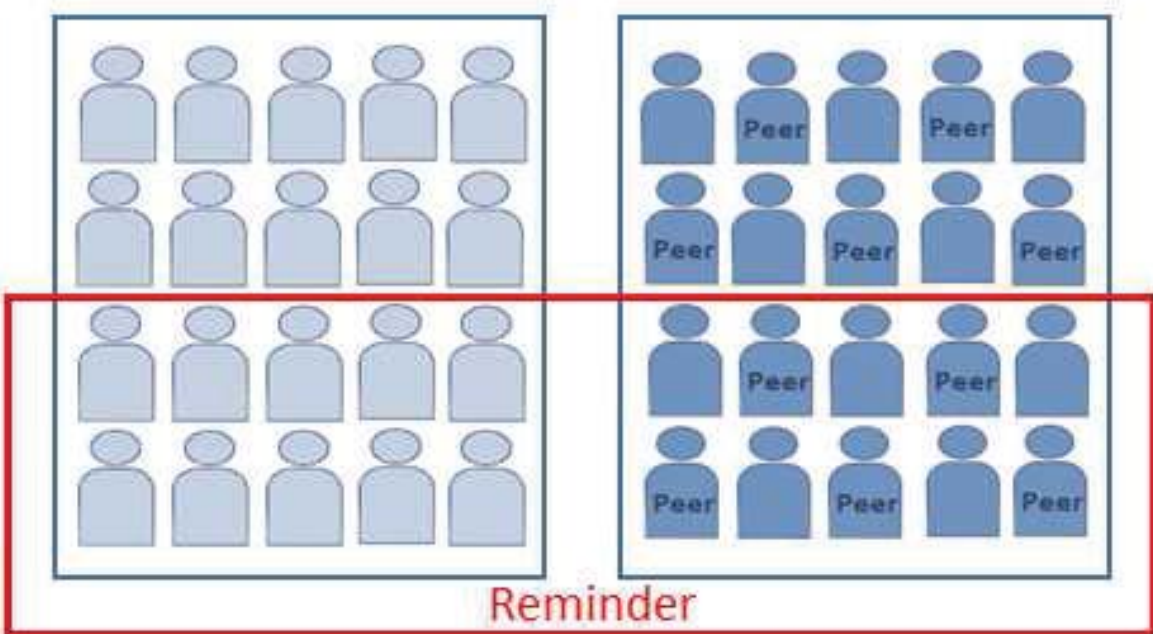

Study participants are randomly assigned to one of three treatment arms: Control (pure control), Workshop (workshop only), and Workshop Plus (workshop + plan making). A random subset of job seekers in the Workshop Plus group were additionally asked to identify a peer. Participants across the Workshop and Workshop Plus groups were further randomized to receive text-message reminders.

Figure A1: Study Design 


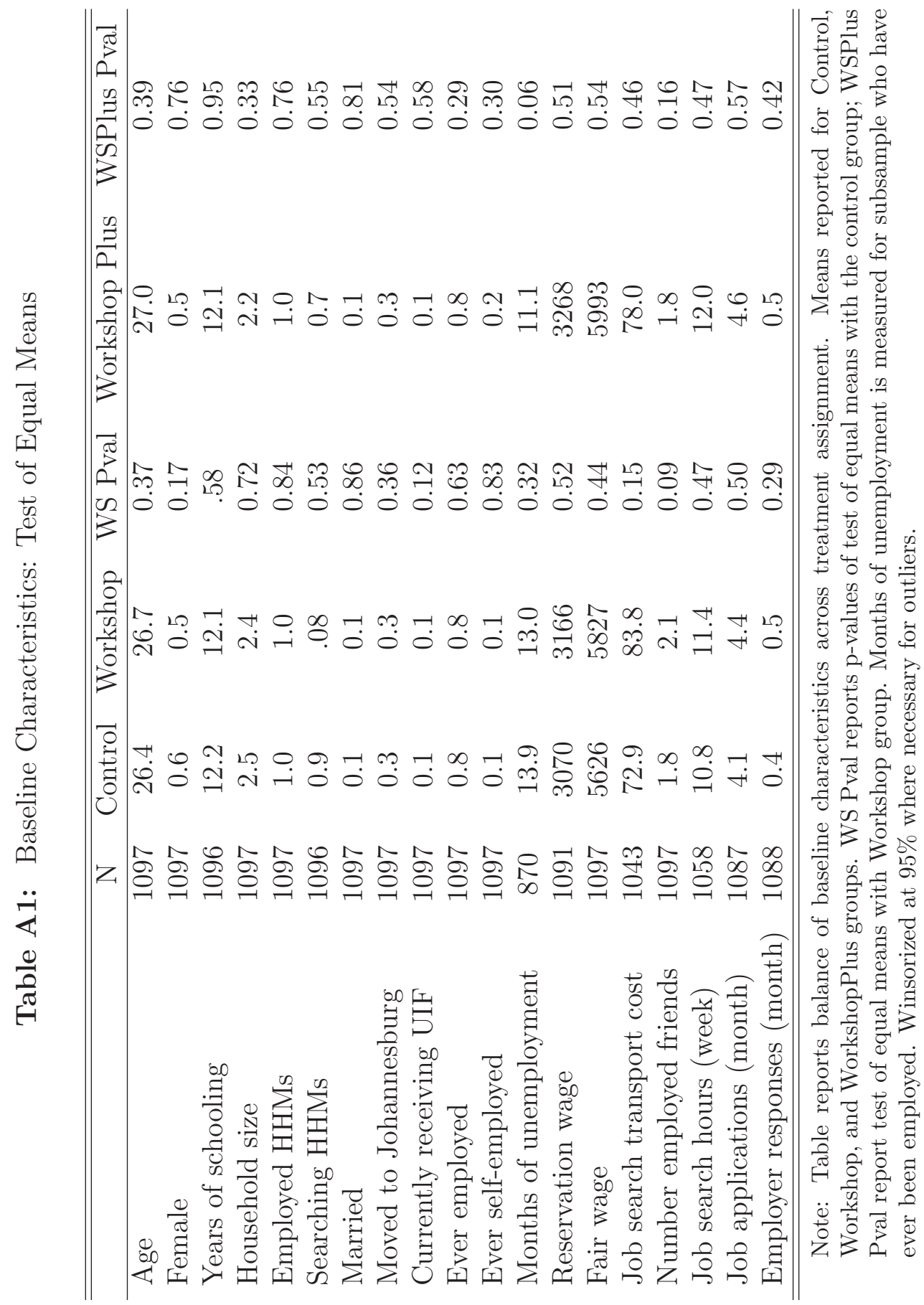


Table A2: Attrition by Treatment

\begin{tabular}{lcccccc}
\hline \hline & Sample & Control & WS Basic & WS Plus & Pval Basic & Pval Plus \\
\hline Attrition Wave 1 & 0.05 & 0.05 & 0.04 & 0.06 & 0.52 & 0.31 \\
Attrition Wave 2 & 0.15 & 0.15 & 0.15 & 0.15 & 0.91 & 0.89 \\
\hline \hline
\end{tabular}

Note: Table reports attrition as a percentage of the sample in the Control group, Workshop only group, and workshop Plus group. Pval Basic reports the Pvalue of test of attrition in the Workshop Basic group to the Control: Pval Plus reports p-value of test of attrition in Workshop Plus to Workshop Basic. 


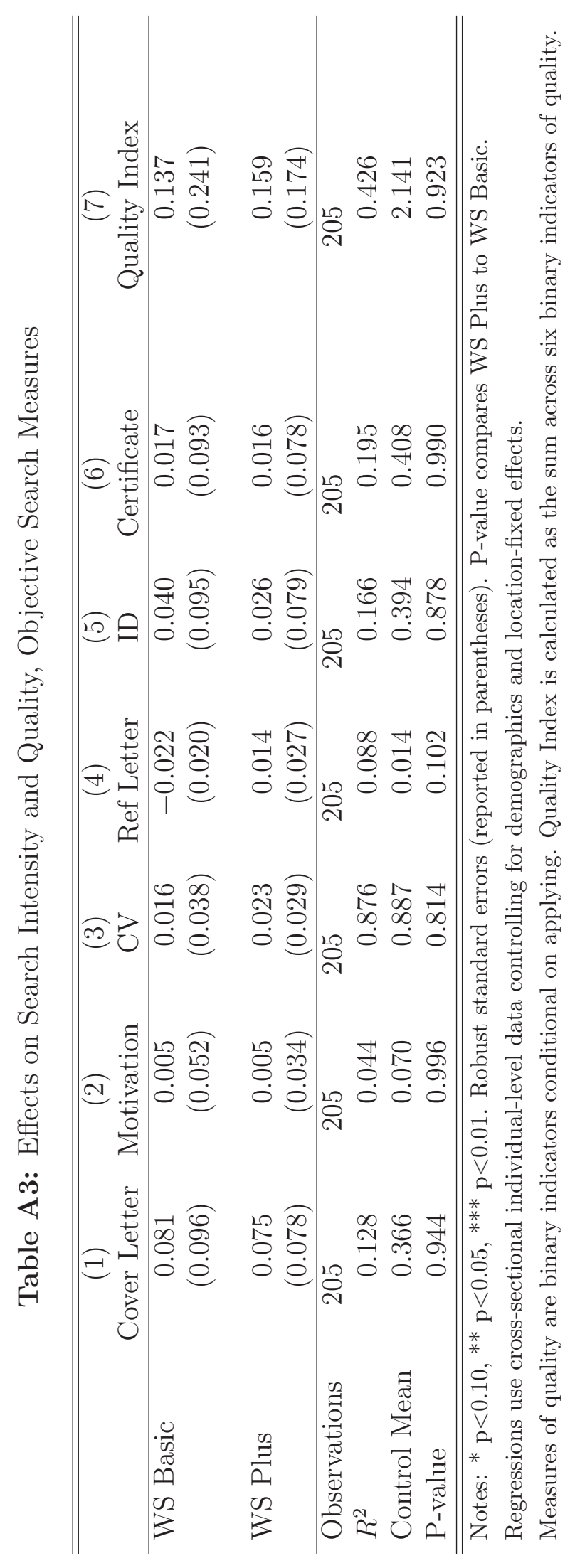


Table A4: Effects on Frequency of Search Channel Use: Interval Regression

\begin{tabular}{lcccccc}
\hline \hline & $(1)$ & $(2)$ & $(3)$ & $(4)$ & $(5)$ & $(6)$ \\
& Empl Agency & Drop CVs & Place Ad & Answer Ad & Search Online & Fam/Friends \\
\hline WS Basic & 0.003 & -0.176 & 0.244 & -0.096 & 0.250 & 0.014 \\
& $(0.258)$ & $(0.183)$ & $(0.388)$ & $(0.200)$ & $(0.398)$ & $(0.362)$ \\
WS Plus & $0.770^{* * *}$ & $0.430^{* * *}$ & 0.320 & $0.570^{* * *}$ & $1.226^{* * *}$ & -0.081 \\
& $(0.232)$ & $(0.164)$ & $(0.303)$ & $(0.180)$ & $(0.329)$ & $(0.305)$ \\
Covariates & $Y e s$ & $Y e s$ & $Y e s$ & $Y$ Yes & Yes & Yes \\
\hline $\mathrm{N}$ & 1937 & 1936 & 1934 & 1927 & 1931 & 1926 \\
\hline \hline
\end{tabular}

Notes: ${ }^{*} \mathrm{p}<0.10,{ }^{* *} \mathrm{p}<0.05,{ }^{* * *} \mathrm{p}<0.01$. Regressions use panel data over two follow-up periods.

Interval regressions are ordered probit estimators in which the thresholds are specified rather than estimated.

We specify the thresholds for the ordinal search frequency variable using the number of weekly search days

that separate the specified survey response categories. The estimated coefficients are directly comparable

to those that would have been obtained from an OLS regression on a continuous weakly search days dependent variable.

Standard errors (reported in parentheses) are clustered at the individual level.

All regressions control for location-fixed effects and baseline value of the outcome variable. 
Table A5: Effects of Reminders on Search and Employment Outcomes

\begin{tabular}{|c|c|c|c|c|c|}
\hline & \multicolumn{2}{|c|}{ Search } & \multicolumn{3}{|c|}{ Employment } \\
\hline & (1) & $(2)$ & $(3)$ & (4) & $(5)$ \\
\hline & Search Hours & Applications & Empl Responses & Job Offers & Employed \\
\hline WS Basic & $\begin{array}{c}-0.344 \\
(1.065)\end{array}$ & $\begin{array}{c}0.093 \\
(0.316)\end{array}$ & $\begin{array}{c}0.049 \\
(0.071)\end{array}$ & $\begin{array}{c}0.025 \\
(0.027)\end{array}$ & $\begin{array}{c}0.015 \\
(0.030)\end{array}$ \\
\hline WS Plus & $\begin{array}{r}-0.724 \\
(0.890)\end{array}$ & $\begin{array}{c}0.496^{*} \\
(0.282)\end{array}$ & $\begin{array}{c}0.089 \\
(0.061)\end{array}$ & $\begin{array}{l}0.077^{* * *} \\
(0.026)\end{array}$ & $\begin{array}{r}0.043^{*} \\
(0.025)\end{array}$ \\
\hline WS Basic X Reminder & $\begin{array}{c}0.939 \\
(1.520)\end{array}$ & $\begin{array}{c}0.076 \\
(0.523)\end{array}$ & $\begin{array}{c}-0.200^{* *} \\
(0.099)\end{array}$ & $\begin{array}{r}-0.007 \\
(0.038)\end{array}$ & $\begin{array}{c}0.011 \\
(0.046)\end{array}$ \\
\hline WS Plus X Reminder & $\begin{array}{c}0.438 \\
(0.977)\end{array}$ & $\begin{array}{c}0.354 \\
(0.366)\end{array}$ & $\begin{array}{c}0.032 \\
(0.073)\end{array}$ & $\begin{array}{r}-0.031 \\
(0.030)\end{array}$ & $\begin{array}{c}0.012 \\
(0.031)\end{array}$ \\
\hline Observations & 1886 & 1895 & 1894 & 1881 & 1969 \\
\hline$R^{2}$ & 0.092 & 0.319 & 0.111 & 0.022 & 0.024 \\
\hline Control Mean & 14.095 & 3.835 & 0.544 & 0.130 & 0.115 \\
\hline
\end{tabular}

Notes: ${ }^{*} \mathrm{p}<0.10,{ }^{* *} \mathrm{p}<0.05,{ }^{* * *} \mathrm{p}<0.01$. Regressions use panel data over two follow-up periods.

Standard errors (reported in parentheses) are clustered at the individual level.

Coefficients on Reminder interaction terms express the additional value of the reminder.

All regressions control for location-fixed effects and baseline value of the outcome variable.

Outcome variables are winsorized at the $5 \%$ level. 
Table A6: Effects of Peer Support on Search and Employment Outcomes

\begin{tabular}{|c|c|c|c|c|c|}
\hline & \multicolumn{2}{|c|}{ Search } & \multicolumn{3}{|c|}{ Employment } \\
\hline & $(1)$ & $(2)$ & $(3)$ & (4) & $(5)$ \\
\hline & Search Hours & Applications & Empl Responses & Job Offers & Employed \\
\hline WS Basic & $\begin{array}{c}0.023 \\
(0.897)\end{array}$ & $\begin{array}{c}0.118 \\
(0.273)\end{array}$ & $\begin{array}{c}-0.028 \\
(0.059)\end{array}$ & $\begin{array}{c}0.022 \\
(0.022)\end{array}$ & $\begin{array}{c}0.020 \\
(0.025)\end{array}$ \\
\hline WS Plus & $\begin{array}{r}-0.217 \\
(0.907)\end{array}$ & $\begin{array}{c}0.392 \\
(0.305)\end{array}$ & $\begin{array}{c}0.051 \\
(0.064)\end{array}$ & $\begin{array}{c}0.050^{* *} \\
(0.025)\end{array}$ & $\begin{array}{c}0.059^{* *} \\
(0.027)\end{array}$ \\
\hline WS Plus x Peer & $\begin{array}{r}-0.494 \\
(0.974)\end{array}$ & $\begin{array}{c}0.545 \\
(0.366)\end{array}$ & $\begin{array}{l}0.095 \\
(0.074)\end{array}$ & $\begin{array}{c}0.019 \\
(0.030)\end{array}$ & $\begin{array}{r}-0.019 \\
(0.031)\end{array}$ \\
\hline Observations & 1886 & 1895 & 1894 & 1881 & 1969 \\
\hline$R^{2}$ & 0.092 & 0.320 & 0.110 & 0.021 & 0.024 \\
\hline Control Mean & 14.095 & 3.835 & 0.544 & 0.130 & 0.115 \\
\hline
\end{tabular}

Notes: ${ }^{*} \mathrm{p}<0.10,{ }^{* *} \mathrm{p}<0.05,{ }^{* * *} \mathrm{p}<0.01$. Regressions use panel data over two follow-up periods.

Standard errors (reported in parentheses) are clustered at the individual level.

Coefficient on Peer interaction term expresses the additional value of the peer support.

All regressions control for location-fixed effects and baseline value of the outcome variable.

Outcome variables are winsorized at the $5 \%$ level. 


\section{JOB SEARCH ACTION PLAN}

Name:

Phone No:

Instructions: We invite you to write your personal job search plan for a typical week. Please be specific and make realistic goals.

\begin{tabular}{|c|c|c|c|}
\hline Day & $\frac{\text { Time of day }}{\text { (Ex: Morning) }}$ & $\frac{\text { Activity }}{\text { (Ex: search newspaper / internet, drop CVs) }}$ & $\frac{\text { Details }}{\text { (Which newspaper? Where drop CVs?) }}$ \\
\hline Monday & & & \\
\hline Tuesday & & & \\
\hline Wednesd & & & \\
\hline Thursday & & & \\
\hline Friday & & & \\
\hline Saturday & & & \\
\hline Sunday & & & \\
\hline
\end{tabular}

\section{Weekly Goals} job opportunities.

1) Each week I plan to identify

2) Each week I plan to submit

3) Each week I plan to search for work for applications.

4) 